\title{
Research on the Construction and Pushing Service Mechanism of Digital Education Resources in the Big Data Era
}

\author{
Yanxia $\mathrm{Wu}^{1, \text { a }}$, Weicai Song ${ }^{2, \mathrm{~b}}$ \\ ${ }^{1}$ Institute of humanities, Jiangxi University of Traditional Chinese Medicine, Nanchang, China \\ ${ }^{2}$ Institute of Computer Science, Jiangxi University of Traditional Chinese Medicine, Nanchang, China \\ awuyanxia2000@sina.com, bsongweicai2000@sina.com
}

Keywords: big data; information technology; digital education resources; construction and pushing service mechanism

\begin{abstract}
In the different stages of the development of information technology, the digital education resources have different forms of expression. The digital education resources in the era of big data have the following characteristics: the data volume is huge, the types are numerous, the flow speed is fast, and the value density is low. However, while the digital education resources in the era of big data are exploding, they are in an embarrassing situation where demand and supply do not match. This study will propose the construction and push service mechanism of digital education resources from the perspective of big data, in order to improve the utilization efficiency of the digital education resources.
\end{abstract}

\section{Introduction}

The digital education resources in the era of big data have the following characteristics: the data volume is huge, the types are numerous, the flow speed is fast, and the value density is low. While the digital education resources in the era of big data are exploding, digital education resources are in an embarrassing situation where demand and supply do not match. How to solve this problem is a serious challenge in the era of big data.

\section{Research Background}

Digital education resources are an important part of educational information construction. At different stages of information technology development, digital education resources have different forms of expression, as shown in Table 1:

According to Table 1, it can be seen that with the development of information technology, the era of big data has arrived. Big data refers to data sets that are difficult to extract, manage, and process with conventional software tools ${ }^{[1]}$. Digital education resources are designed and developed to achieve a certain teaching purpose, support the development of teaching activities, and store the course materials in digital form ${ }^{[2]}$. As the carrier of teaching content, digital education resources are directly oriented to teachers and students. The quality of their services directly affects usability. Digital education resources in the era of big data mainly include resource libraries, digital libraries, online courses, digital websites, and special websites. The digital education resources service process can collect a large amount of data, many types, fast flow, low value density, digital education resource services based on data, the mining and utilization of these data will improve digital education resources to a certain extent service. However, while the digital education resources in the era of big data are exploding, "we are drowning in the ocean of information, but we are full of knowledge and hunger." Digital education resources are in a state of unmatched demand and supply, mainly as follows: 
Table 1 Expressions of digital educational resources

\begin{tabular}{|l|l|}
\hline $\begin{array}{l}\text { Development of } \\
\text { information } \\
\text { technology }\end{array}$ & The expression of digital educational resources \\
\hline $\begin{array}{l}\text { Web1.0 } \\
\text { The era of } \\
\text { computer network } \\
\text { technology) }\end{array}$ & $\begin{array}{l}\text { Multi-media and networked digital education resources: the development } \\
\text { of and supply of knowledge resources such as case libraries, material } \\
\text { libraries, special resource libraries, digital libraries, and subject teaching } \\
\text { tools. }\end{array}$ \\
\hline $\begin{array}{l}\text { Web2.0 } \\
\text { The era of mobile } \\
\text { internet } \\
\text { technology) }\end{array}$ & $\begin{array}{l}\text { Generating and opening digital education resources: openness, sharing, } \\
\text { collaboration, and innovation are fundamental characteristics. Knowledge } \\
\text { resources are organized according to needs, with intellectual resources } \\
\text { sharing as the core, and interactive tools are fully applied. }\end{array}$ \\
\hline $\begin{array}{l}\text { Web3.0 } \\
\text { (Big Data Era) }\end{array}$ & $\begin{array}{l}\text { The types of digital education resources are much larger and larger: resource } \\
\text { libraries, digital libraries, online courses, digital websites, and special websites have } \\
\text { become common resource types, and digital resources are massively produced. At } \\
\text { the same time, virtual resource environments such as virtual museums, virtual } \\
\text { libraries, and virtual laboratories are gradually running online. }\end{array}$ \\
\hline
\end{tabular}

\subsection{Resources are heterogeneous, redundant, and lacking in semantics}

Massive digital education resources involve a variety of heterogeneous data resources, which can be called multi-source heterogeneous data. For example, from the basic format of data, there are data formats, text formats, and XML formats; from the perspective of data structure, there are structured data, semi-structured data, and unstructured data; from the data semantics, there are the underlying raw data collected and the high-level generalized data after the data aggregation, etc., where the underlying raw data has huge data redundancy and lack of semantics.

\subsection{The resource model is not balanced}

Resources based on traditional teaching modes (such as texts, pictures, simple e-books, etc.) are many, but resources (multimedia, interactivity, etc.) suitable for teaching applications in an information environment are few;

\subsection{The universality of resources is poor}

There are many resources suitable for individual applications (individual classrooms, individual subjects, individual teachers), and there are fewer digital resources for supporting teaching materials, system development, and universal application.

\subsection{The timeliness of digital education resources is poor and lacks dynamic adaptability}

In order to solve the current dilemma of digital education resources, domestic and foreign scholars have done a lot of related research.

Around the mid-to-late 1990s, foreign countries began to study the effective use of digital education resources, and a series of research papers appeared, and some related academic seminars were held ${ }^{[3]}$. There are three distinctive features in the construction and promotion of digital education resources in developed countries: attach importance to the leading role of the government, coordinate the development of digital education resources; focus on solving the problem of resource standardization, resource access system construction, diversification of evaluation methods; attach importance to intercollegiate and international cooperation on high quality education resources.

The effective use of domestic digital education resources was studied in 2000, Including the construction of resource platform in the context of big data ${ }^{[4]}$, educational resource organization model ${ }^{[5]}$, integration of educational resources ${ }^{[6]}$, resource evaluation model ${ }^{[7]}$, resource sharing strategy ${ }^{[8]}$, the New ideas of big data in promoting the balance of educational resources ${ }^{[9]}$ and so on Significant shortcomings in the construction and promotion of digital education resources in China: Firstly the lack of unified standards and technical specifications for the construction of digital resources. Resource developers mostly perform according to their own understanding, so a large 
number of digital resources of different levels, different attributes and different structures emerged, so that there are not only different descriptions, loose distribution, attribute indexing and different fragmentation granularity, but also difficulties to convert between different platforms and systems, resulting in limited use of resources and sharing; Secondly the lack of digital resource construction evaluation criteria and access. The mechanism has led to the construction of digital resources, but most of them are repeated at low levels; there is no effective mechanism for the promotion of digital resources for basic education. Because who invests and who benefits, resources are often limited to use within a certain collaborative organization or unit, cannot be shared in a wider range, and performance is not high.

In view of the above research, this study will propose the construction of digital education resources and the push service mechanism---resources public construction and sharing from the perspective of big data, in order to improve the utilization efficiency of the digital education resources.

\section{Research Content}

\subsection{Research objects}

The construction of digital education resources and the push service mechanism in the era of big data - resources public construction and sharing.

\subsection{Overall framework}

In order to make the construction and delivery service mechanism of digital education resources in the era of big data in the future construction, we can make overall plans and take all factors into consideration, based on actual and scientific advancement. Now based on the research status at home and abroad and combined with the author's long-term research, we propose the overall framework of the digital education resources in the era of big data.

The public construction and sharing mechanism system is divided into five layers:decisionmaking and construction layer, digital resource layer, cloud platform layer, user interface layer, and user(as shown in Figure 1). The specific functions are shown in Figure 1.

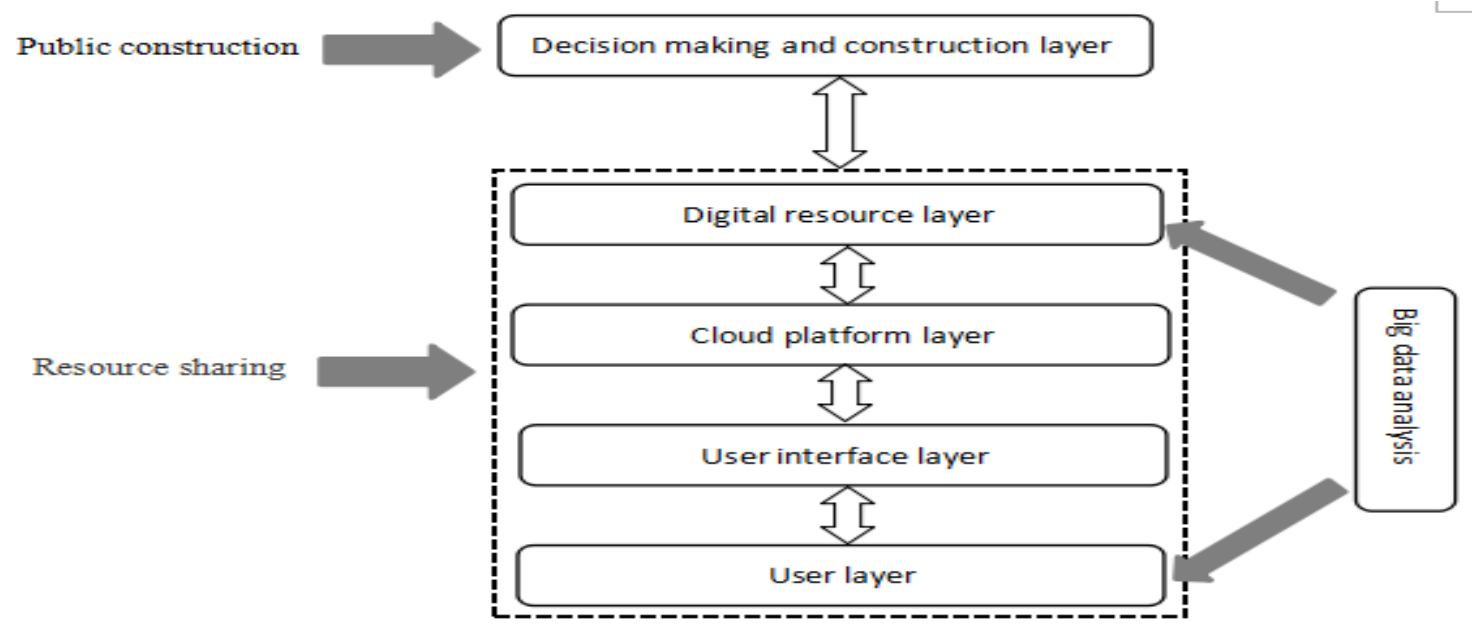

Figure 1 the systematic frame of public construction and sharing mechanism 


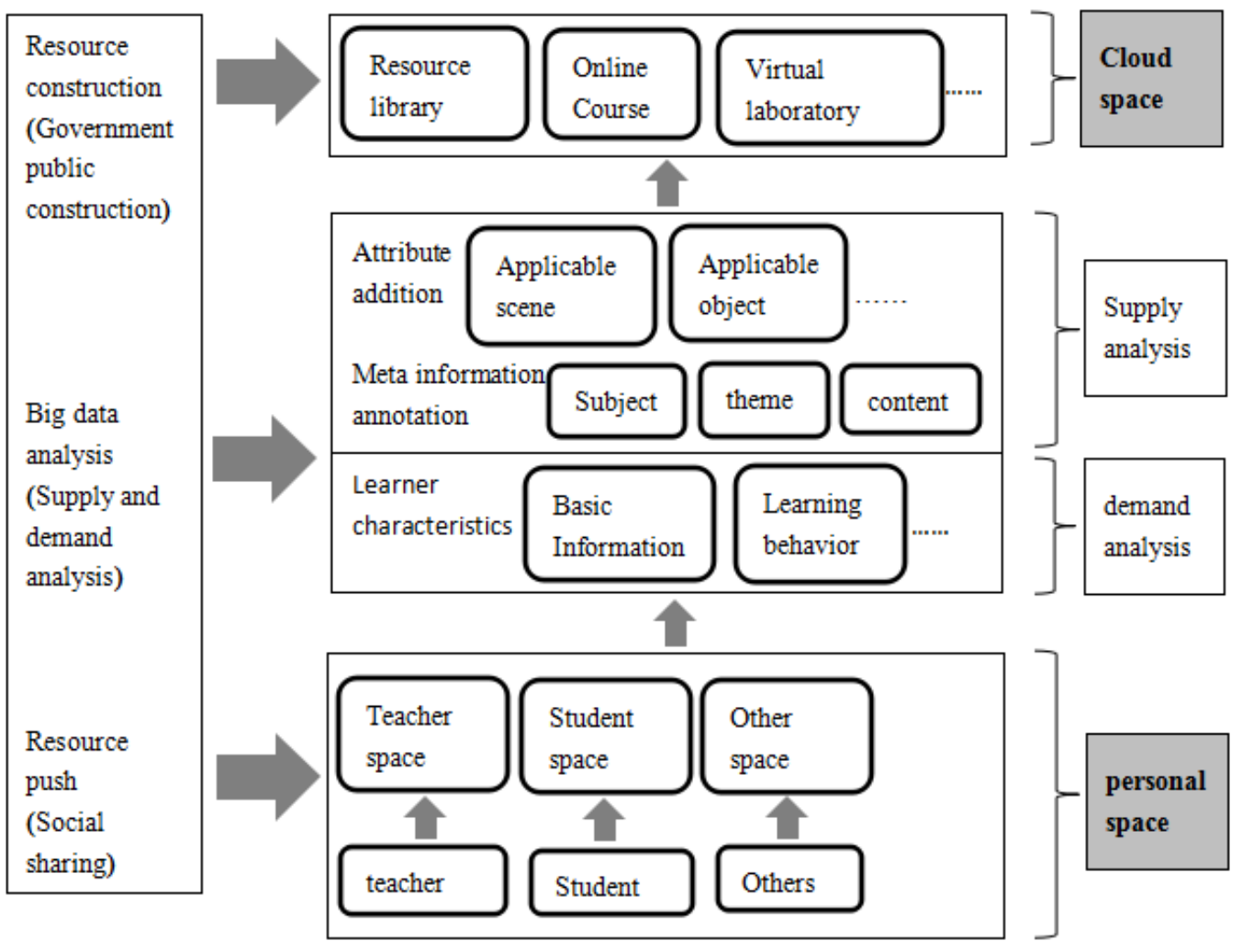

Figure 2 the functional frame of public construction sharing mechanism

\section{The Basic Idea}

The realization of the value of digital education resources depends on two points: First, the extent to which resources meet the requirements of "quality", and second, the extent to which resources are effectively pushed, and the public construction and sharing mechanism gives a good solution. The function of the public construction and sharing mechanism is shown in Figure 2.

"Public construction" means that the government is the only resource construction planner and decision maker. The key to public construction is to ensure deep compatibility of resources with uniform standards and norms, and to avoid low-level redundant construction. The government undertakes the main responsibility of top-level design, capital investment and overall coordination, with public finance input as the main source of funds, coordinating the implementation of social forces (colleges, scientific research institutions, enterprises, individuals) and building a sustainable resource construction mechanism for resource generation. "Sharing" means that all members of the society can obtain high-quality digital resources jointly generated by the government's unified design and planning and social wisdom. The public construction and sharing push mechanism is based on big data, the government builds a cloud platform, realizes the unified architecture, unified storage, unified management and unified access of massive digital resources, solves the problem of efficiency dispersion brought by multi-level platforms; integrates various resource platforms at various levels, form a unified resource push mode to fully meet the needs of various resource users. Integrate resource management entrance and application exit, change the status quo of the resource platform "Flying in the sky", and fundamentally improve the efficiency of resource services.

In the functional frame of the public construction and sharing mechanism, big data analysis technology is an important soil for the operation and development of the public construction and sharing mechanism. Its advantage is to realize the precision of resource supply by collecting and analyzing various behavior data of users. Big data supply analysis promotes the personalized representation of digital educational resources by improving the personalized attribute tags of digital education resources (such as resource application scenarios, applicable objects, applicable content, etc.). The resource feature model is constructed by analyzing, analyzing, constructing, 
drawing and displaying resources and their interconnections with big data analysis of the subject, theme and content of digital education resources. Big data needs analysis through basic information about individuals (such as age, gender, family relationship, etc.) and resource interaction behavior information (such as search, download, broadcast, evaluation and other behavioral process information and achievements, works and other behavioral outcome information, etc.), interpersonal Big data analysis of interaction behavior information (such as teacher-student interaction, student interaction, teacher interaction process and behavior information), constructing a learner feature model including knowledge ability level, learning style, learning interest, learning performance, etc. The learner's personalized learning resources and the push of adaptive learning services provide data support and reference. Provide support for the accurate delivery of resources and promote the individualized development of learners.

\section{Conclusion}

This study first sorts out the different forms of digital education resources at different stages of information technology development. It can be seen that information technology has entered the era of big data. On the basis of the above, the questions raised by digital education resources in the era of big data are: (1) resources are heterogeneous, redundant, and lack of semantics; (2) resource patterns are unbalanced; resources based on traditional teaching models (such as texts, pictures, There are many simple e-books, etc., but there are few resources (multimedia, interactivity, etc.) suitable for teaching applications in an information environment; (3) The universality of resources is poor. There are many resources suitable for individual applications (individual classrooms, individual subjects, individual teachers), but there are fewer supporting resources, system development, and digital resources suitable for general application; (4) Digital education resources have poor timeliness and lack of dynamic adaptability. And put forward a specific solution: the construction of digital education resources and the push service mechanism in the era of big data.

\section{References}

[1] SNIJDERS C, MATZAT U, REIPS U D."Big data":big gaps of knowledge in the field of internet science [J]. International journal of internet science, 2012, 7(1): 1-5.

[2] Yu liang,Chen Shijian,Wu Di. pluralism,Co-creation and Accurate push: The new development of digital education resources [J]. China Educational Technology, 2016(4):52-57.

[3] $\mathrm{Wu} \mathrm{Di}, \mathrm{Yu}$ Liqin, Li Congcong, Yu Xiao Rong. Path and Enlightenment of educational informatization policy in developed countries [J].E-education Research, 2017(9):5-11.

[4] Rong Cuiqin, Zhang Yong, Du Jing. Construction of characteristic resource service platform based on big data [J]. library work and study,2015,(4): 29-32.

[5] Liu Hu. Research on the organization model of educational resources based on Metadata [J].China Adult Education; 2011, (6): 28-30.

[6] Liu Xiaoying,Wen Xiaoting.Research on the integration of digital education resources in the era of big data [J].Library,2015,(2): 58-61.

[7] Cheng Gang, Kao Hui, Yu Sheng Quan.Evaluation model of mobile learning resources based on real user reviews information [J].Modern Distance Education,2014,(1): 43-53.

[8] He Jianxin.Discussion on digital resources sharing strategy of University Library in big data Era [J].Modern Information, 2014, (9): 101-104.

[9] Rong Cuiqin, Zhang Yong, Du Jing. Construction of characteristic resource service platform based on big data [J].library work and study, 2015, (4): 29-32. 